\title{
Negative synergy: hearing loss and aging
}

\author{
Comentado por: Elisiane Crestani de Miranda ${ }^{1}$, Alessandra Spada Durante ${ }^{2}$
}

Schum JD, Beck DL. Negative synergy: hearing loss e aging. Audiology Online [Internet]. June 23, 2008. [cited 2009 Jul 12]. Available from: www.audiologyonline.com/articles.

Este artigo aborda as modificações no processo de compreensão de fala com o envelhecimento. Os autores pretendem detalhar o processamento sensorial (bottom-up) e cognitivo (top-down) da fala, destacando a relação interativa e complementar necessária para o sucesso da comunicação.

É amplamente descrito na literatura que as medidas audiológicas básicas não refletem com precisão a habilidade e/ ou a dificuldade de compreensão de fala de indivíduos com deficiência auditiva, sendo necessário utilizar testes/protocolos que melhor expressem os problemas de inteligibilidade de fala nas situações do cotidiano. A literatura incentiva a utilização de testes com sentenças, principalmente na presença de ruído competitivo. Entretanto, outros aspectos pragmáticos da audição devem ser explorados.

Para que todo processo seja bem sucedido, o ouvinte deve acumular a base sensorial da informação (bottom-up) ao longo do tempo e interpretar cognitivamente (top-down) a intenção do falante. $O$ discurso ocorre rapidamente a um ritmo estabelecido pelo interlocutor; assim, o ouvinte desafiado a acumular informações ao longo do tempo, a uma taxa escolhida pelo falante, pode não acumular o significado com rapidez suficiente, levando ao insucesso na comunicação.

A reconstrução dos sons de fala ao longo do tempo em palavras significativas é um processo complexo e torna-se altamente problemático quando associado à deficiência auditiva (DA) e às alterações cognitivas relacionadas com a idade.

Durante a escuta em ambiente acústico complexo com várias fontes sonoras, o sistema cognitivo automaticamente faz tentativas de separar as fontes de ruídos, para ouvir uma fonte específica de interesse. Uma grande ativação cerebral é exigida para ouvir em ambientes complexos e desconstruir o som de maneira significativa.

O principal efeito de perda auditiva neurossensorial é a degradação do input auditivo e envolve mais do que uma diminuição na audibilidade ${ }^{(1)}$. Para compreender a fala em

(1) Pós-granduanda (Doutorado) em Ciências dos Distúrbios da Comunicação Humana - Campo Fonoaudiológico pela Universidade Federal de São Paulo - UNIFESP - São Paulo (SP), Brasil; Professora do Curso de Fonoaudiologia da Faculdade de Ciências Médicas da Santa Casa de São Paulo - FCMSCSP - São Paulo (SP), Brasil.

(2) Doutora, Professora do Curso de Fonoaudiologia da Faculdade de Ciências Médicas da Santa Casa de São Paulo - FCMSCSP - São Paulo (SP), Brasil. Endereço para correspondência: Elisiane Crestani de Miranda. Faculdade de Ciências Médicas da Santa Casa de São Paulo. R. Dr. Cesário Mota Júnior, 61, $8^{\circ}$ andar, Vila Buarque, São Paulo (SP), Brasil, CEP: 01221-020. E-mail: lisi_miranda@hotmail.com ambientes ruidosos o individuo idoso com perda auditiva neurossensorial necessita de um maior esforço perceptual do que um indivíduo adulto. Nestes ambientes, o sistema auditivo envelhecido, possivelmente, ativa processos compensatórios para obter melhor desempenho comunicativo. Desse modo, mais recursos cognitivos são desviados para a percepção (identificação) da palavra, permanecendo poucos recursos disponíveis para outras tarefas de nível cognitivo mais alto, tais como: compreensão e memória das palavras que foram identificadas.

Os problemas mais comuns na pessoa idosa incluem: esquecimento, dificuldade em encontrar palavras, tempo de reação diminuído e dificuldade em aprender novas tarefas. As alterações e redução de neurotransmissores contribuem para desacelerar o tempo de realização neural.

Muitos pacientes com audição prejudicada também sofrem com declínio nas habilidades do processamento cognitivo; assim, haverá limites para os benefícios proporcionados pelas próteses auditivas, especialmente em ambientes complexos e desafiantes da comunicação.

As próteses auditivas podem facilmente compensar a sensibilidade (isto é, limiar), mas não resolvem os problemas decorrentes do processamento cognitivo dos sons de fala. Relações importantes entre a implementação do estado cognitivo e processamento não-linear de sinais das próteses auditivas têm sido exploradas ${ }^{(2-4)}$.

A tecnologia avançada de próteses auditivas não garante o bom desempenho para os pacientes. Contudo, a inclusão de algoritmos redutores de ruído, comunicação sem fio entre os aparelhos e a direcionalidade nas informações de fala são benéficas.

Os processos top-down e bottom-up devem ser integrados efetivamente para maximizar a percepção discurso. Um déficit em qualquer entrada sensorial e cognitiva dos sons da fala cria obstáculos difíceis para a comunicação. Quando ambos os déficits estão presentes, como acontece muitas vezes nos pacientes idosos com perda auditiva, alterações na comunicação e vida diária precisam ser administradas com maior atenção.

A administração eficaz destes problemas pode ser definida como reabilitação aural, processo de longo prazo que visa alcançar o sucesso auditivo para pacientes com audição prejudicada, com e sem amplificação, aprendendo a usar satisfatoriamente a audição. As diferenças individuais das funções cognitivas precisam ser consideradas, criando, assim, reais oportunidades para que esses pacientes desenvolvam as suas máximas potencialidades auditivas e cognitivas. 


\section{REFERÊNCIAS}

1. Moore B. Cochlear Hearing Loss: Physiological, psychological and technical issues. Hoboken: John Wiley \& Sons; 2007.

2. Foo C, Rudner M, Rönnberg J, Lunner T. Recognition of speech in noise with new hearing instrument compression release settings requires explicit cognitive storage and processing capacity. J Am Acad Audiol. 2007;18(7):618-31.
3. Gatehouse S, Naylor G, Elberling C. Benefits from hearing aids in relation to the interaction between the user and the environment. Int $\mathrm{J}$ Audiol. 2003;42 Suppl 1:S77-S85.

4. Gatehouse S, Naylor G, Elberling C. Linear and non-linear hearing aid fittings - 2. Patterns of candidature. Int J Audiol. 2006;45(3):153-71. 